Ambiente \& Água - An Interdisciplinary Journal of Applied Science
ISSN 1980-993X - doi:10.4136/1980-993X
www.ambi-agua.net
E-mail: ambi.agua@gmail.com

\title{
Mecanismos informales de asignación y reasignación de aguas públicas e ineficacia del derecho en el oeste árido argentino
}

\author{
doi: 10.4136/ambi-agua.1537 \\ Received: 10 Oct. 2014; Accepted: 20 Jan. 2015 \\ Liber Martin*; Mauricio Pinto \\ Universidad Nacional de Cuyo (UNCuyo), CONICET, Mendoza, Argentina \\ *Autor correspondiente: e-mail: libermartin@hotmail.com, \\ mpinto@fca.uncu.edu.ar
}

\section{RESUMEN}

El presente trabajo tiene como objetivo principal analizar los mecanismos informales de asignación y reasignación de aguas públicas en el oeste argentino desde una concepción integral del derecho. Se revisa la práctica de los usos informales, su lógica pero ineficaz represión tanto como su regularización desde un diseño metodológico observacional no experimental basado en el uso de estrategias cualitativas. El trabajo indaga en el funcionamiento de los mecanismos y prácticas administrativas desarrollados en ausencia de ley y contra la ley, tanto a nivel legal y reglamentario como distributivo. Las conclusiones ponen de relieve las tensiones y contradicciones de estos mecanismos al amparo del sistema legal formal evidenciando una crisis tanto de eficacia como de legitimidad del derecho y del Estado administrador del agua pública.

Palabras clave: Argentina, eficacia, uso del agua.

\section{Mecanismos informais para alocação e realocação das águas públicas e ineficácia do direito no oeste árido da Argentina}

\section{RESUMO}

Este trabalho teve como objetivo principal analisar os mecanismos informais de alocação e realocação de águas públicas no oeste da Argentina a partir de uma concepção holística do direito. Revisaram-se os usos informais, sua repressão lógica, porém ineficaz e os processos contínuos de regularização baseados em estudo observacional não experimental e em estratégias qualitativas. Assim, o trabalho investigou o funcionamento dos mecanismos e práticas administrativas desenvolvidas na ausência de lei e fora da lei, tanto em nível legal e regulamentário como distributivo. As conclusões destacam as tensões e contradições destes mecanismos no âmbito do sistema jurídico formal, demonstrando uma crise da eficácia e da legitimidade tanto do direito quanto do Estado na administração das águas públicas.

Palavras-chave: Argentina, eficácia, uso da água. 


\title{
Non formal mechanisms for public water allocation and the ineffectiveness of law in arid western Argentina
}

\begin{abstract}
This work analyzed the informal mechanisms of public water allocation and reallocation in western Argentina from a holistic conception of law. The paper refers to informal uses, its logical but ineffective repression and the continuous regularization processes from a non-experimental observational method based on the use of qualitative strategies. The research work focused on the operation of water allocation mechanisms and management practices developed in the absence of law and against the law, at both the delivery and regulatory levels. The findings highlight the tensions and contradictions of these mechanisms under the formal legal system, demonstrating the crisis of both effectiveness and legitimacy of the law and the State in managing public waters.
\end{abstract}

Keywords: Argentina, effectiveness, water rights, water usage.

\section{INTRODUCCIÓN}

En la utilización del recurso hídrico, como en la mayoría de las actividades humanas regladas puede analizarse un doble orden de conductas en relación con el fenómeno jurídico: el de la formalidad, es decir aquellas situaciones donde las conductas se manifiestan acorde a la institucionalidad signada por el derecho; y el de la informalidad, donde la sociedad actúa al margen de las previsiones normativas formalmente vigentes.

La discusión sobre la gobernabilidad de las aguas hace usualmente, casi exclusiva referencia al sistema formal, es decir, al conjunto de reglas y principios articulados a través del sistema de políticas que permite la operación de diferentes agentes en funciones distintas; incluso cuando es común que además de los regímenes de regulación que caracterizan el funcionamiento de los sistemas formales, enraizados en las políticas, exista una variedad de reglas no escritas, consuetudinarias enraizadas en las prácticas, que sostiene y estructura el llamado sistema informal (Allen et al., 2005) y cuya indagación se propone en el presente.

Es que la distancia entre el discurso formal de las normas vigentes y la eficacia social, en el fondo, materializa un problema de creencia en el régimen jurídico, donde la legitimidad fundada mediante la "fe en la legalidad" weberiana (Habermas, 1988) se presenta como insuficiente (Parejo Alfonso, 1989). La eficacia normativa, desde esta perspectiva, contiene elementos sociológicos y políticos que fundamentan la legitimidad del ordenamiento que la contiene (Gardais Ondarza, 2002), y en definitiva brindan exactitud a la norma con respecto a las conductas por ella prevista.

Desde la perspectiva del pluralismo legal se propone precisamente romper con el carácter monopólico de la regulación estatal de las aguas poniendo en valor no sólo la realidad sino la legitimidad de las regulaciones consuetudinarias y ancestrales, muchas de ellas previas incluso a la creación de los Estados. Los estudios de antropología del derecho de aguas avanzan igualmente en la conceptualización de categorías que permiten explicar y dar cuenta de un fenómeno que claramente trasciende el ámbito propio del derecho y categorías clásicas (Boelens et al., 2010).

Un análisis pleno del fenómeno, entonces, exige ir más allá de la norma vigente, especialmente cuando se ha constatado en diversas realidades que las operaciones que pueden existir en las relaciones socioeconómicas incluyen mecanismos informales de asignación de aguas al margen de los supuestos contemplados por la legislación (Reis, 2014; Hernandez-Mora y De Stefano, 2013). 
Estos mecanismos no siempre coinciden con los preceptos formalmente sancionados, y no por ello son necesariamente ignorados por el derecho: las prácticas informales, en muchos casos son combatidas por un conjunto de regulaciones y políticas, disponiéndose sanciones por usos "clandestinos" o "ilegítimos" de las aguas; en otras oportunidades, son toleradas y a veces fomentadas por los sistemas vigentes, hasta el punto de reconocerle efectos jurídicos positivos o algún tipo de significancia para adquirir derechos de aguas.

\section{OBJETIVOS Y JUSTIFICACION}

El régimen federal argentino constituye un prius que determina una heterogeneidad de textos normativos en relación al uso de las aguas, cuya regulación es una facultad de cada provincia o Estado parte de la federación. Dentro de las provincias ubicadas en la zona árida del oeste argentino, ámbito espacial al que se circunscribe la investigación, se contemplan particularidades regulatorias y prácticas de una a otra, aunque en todos los casos se estatuyen instituciones genéricas, como el permiso y/o la concesión, que encauzan la forma de adquirir y ejercer los derechos sobre el uso del agua.

En este marco jurídico y desde esta perspectiva teórica el artículo procura dilucidar los mecanismos informales de asignación y reasignación de aguas que se producen en el oeste árido argentino, y su vinculación con el régimen vigente en las provincias de Mendoza (Ley de Aguas/1884 - LAgM, y Ley de Aguas Subterráneas 4035/1974 - LAgSuM), San Juan (Ley 4392/1978 - Código de Aguas -CAgSJ), La Rioja (Ley 4295/1983 - Código de Aguas-CAgLR), Catamarca (Ley de Aguas 2577/1973 - LAgC), Salta (Ley 7017/1998 Código de Aguas - CAgS) y Jujuy (Ley 161/1950 - Código de Aguas - CAgJ).

Normalmente las referidas prácticas informales a las que con implicancias diversas puede también denominarse según el caso ilegales, alegales o paralegales han sido totalmente ignoradas y subestimadas en su importancia por los estudios jurídicos, a pesar de formar parte innegable del fenómeno jurídico y resultar cruciales para la gestión y administración del agua. Este es el vacío que pretende llenar la presente investigación tomando como objeto de estudio el caso argentino.

\section{MATERIALES Y MÉTODOS}

En base a un diseño metodológico observacional no experimental basado en el uso de estrategias cualitativas, se ha concretado el estudio y correlación de asignación y reasignación de aguas en las provincias áridas del oeste argentino (Mendoza, San Juan, La Rioja, Catamarca, Salta y Jujuy), practicando un análisis que procura trascender el examen dogmático, el artículo indaga en los aspectos menos investigados del fenómeno jurídico, como son los usos espontáneos o informales, para establecer relaciones y correlaciones con el ámbito de la formalidad.

Los aspectos referidos a niveles de eficacia normativa se basan en entrevistas a personas claves, principalmente funcionarios de los organismos estatales y de las organizaciones de usuarios, y profesionales afines a la materia, desarrolladas bajo un modelo metodológico semiestructurado, en el que a la vez que se requería opinión sobre aspectos normativos previamente seleccionados del cuerpo jurídico bajo estudio, se ampliaba el contenido del relevamiento hacia aspectos de interés que surgían de las propias respuestas de los entrevistados. 


\section{RESULTADOS}

\subsection{Los usos informales del agua versus la formalización de los derechos}

Los usos informales del agua implican una realidad que no puede ser ignorada por el Derecho, en cuanto de una $\mathrm{u}$ otra manera lo integra; existen, aunque las actitudes y previsiones normativas hacia los mismos sean variadas.

A diferencia de los usos formalmente constituidos, basados en derechos concedidos por el Estado mediante procedimientos legales, el acceso informal al agua es espontáneo, sin intermediación institucional que los condicione u organice. La informalidad implica la descentralización fáctica en los propios interesados de toda decisión sobre la existencia y alcance del uso, disipándose el rol de decisión estatal que contempla la norma frente a las prácticas individuales e inconexas (Global Water Partnership, 2000).

Sea porque tales usos se configuran en un marco de ilegalidad que requiere represión, o porque socialmente representa un valor a proteger y regular, el acceso informal al agua reviste trascendencia jurídica y merece ser analizado.

La formalización de las prerrogativas de uso del agua mediante su regulación legal, en este sentido, acarrea múltiples ventajas, comenzando por otorgar seguridad jurídica, entendida como una situación de estabilidad y certeza que garantiza la aplicación objetiva de las normas que protegen sus derechos (Kemelmajer de Carlucci, 1993). Los derechos de agua que receptan las legislaciones representan demandas de agua socialmente aceptables y exigibles, y la falta de derechos garantizados deja a las personas expuestas al riesgo de no poder reafirmar sus demandas frente a la cada vez mayor competencia (Naciones Unidas, 2006).

Pero además, la falta de formalización de los usos del agua lleva a una ausencia plena de su gestión integrada, resultando totalmente ajeno a las autoridades estatales las relaciones entre oferta y demanda, y entre estas y las necesidades sociales que deben priorizar las agendas públicas. La relación entre los usos formales y los informales adquiere relevancia, en la medida en que éstos últimos, al no estar incluidos en los registros en que se basa la distribución, se presenten como un menoscabo a los derechos que supuestamente deberían tutelar los primeros.

Un sistema jurídico basado en la asignación formal de derechos de uso de caudales escasos a demandas múltiples, en función de ciertas prioridades públicas fijadas en función de intereses superiores, si convive con la utilización informal de esos mismos caudales que se realizan de hecho y al margen de los balances de asignación, carece de sentido, adquiere un papel meramente simbólico que no cumple otro fin más que el meramente figurativo (Paul, 1990). La estructuración de las conductas socialmente apropiadas en las normas hace posible la integridad y subsistencia de las sociedades (Nino, 1992).

Equivocadamente, desde nuestra perspectiva, se ha sostenido que la informalidad en el acceso al agua se relaciona con pautas de igualdad (Cáceres y Rodriguez Bilella, 2014), resaltándose que en la formalización de los derechos de acceso al agua pueden resultar más favorecidos los sectores más adinerados, con mayor poder o influencia política (Naciones Unidas, 2006).

Incluso, se relaciona fuertemente el desarrollo de mecanismos informales de gestión del agua con la falta de conocimiento por parte de los interesados de las regulaciones e instituciones legalmente constituidas (García Perdomo y Jimenez, 2010), lo que sin dejar de reflejar la actual debilidad institucional del Estado moderno y su instrumentación jurídica (Chevallier, 2011), no brinda justificación alguna a la ineficacia normativa frente al aforismo ignorantia iuris non excusat que caracteriza la fuerza imperativa de las regulaciones vigentes (Madariaga Gutierrez, 1993).

Sin desconocer que los regímenes jurídicos, según los valores en que se funden (Spota, 1975), pueden generar mayores oportunidades de acceso al agua para ciertos sectores que 
pueden estar en pugna de intereses con otros, y que en ese contexto la indagación jurídica que lleva a las decisiones legales no es más que una forma política de ejercicio del poder estatal con la aptitud de autentificar y transmitir verdades (Foucault, 2007), no por ello debe descartarse a priori el rol de las políticas públicas que se producen desde el Estado.

El interés público que caracteriza la asignación de usos del agua no puede ser desplazado desde la función pública, más allá de las falencias que se identifiquen en la misma. Aunque una situación de decadencia estatal pareciera indicar un fortalecimiento de la libertad individual, tal noción es errada en cuanto olvida que dicha libertad no puede desplegarse plenamente cuando la ley no toma a su cargo todo aquello que no es reductible a un intercambio individual de bienes y servicios, es decir, todo aquello que excede la negociación de valores mesurables entre las partes. En estos casos, si los contratos particulares definen lo que la ley debe significar, las partes se encuentran sujetas a objetivos que superan el mero interés patrimonial y su libertad debe resultar avasallada por la realización de tales objetivos (Supiot, 2012).

En el fondo, el acceso al agua no deja de estar vinculado a las reglas de asignación proporcional que debe garantizar la justicia distributiva vigente en cada sociedad (Forero, 2002), proporcionalidad que justificará en cada lugar que existan actividades o sujetos priorizados frente a otros en función del esquema axiológico que justifica la solución adoptada (Martin et al., 2010), lo que impide cualquier análisis desvinculado del contexto y contenido ideológico y político que conforma el ordenamiento jurídico.

En tal sentido, la evolución de los derechos humanos de segunda y tercera generación que marca el sustrato jurídico y político contemporáneo debería potenciar, en las planificaciones y regulaciones estatales, la instrumentación pública del progresivo acceso equitativo al agua (Pinto et al., 2008).

\subsubsection{Los usos fácticos y su represión: una exigencia del modelo centralizado de acceso al agua}

A pesar de que el acceso formal al agua en la región se ajusta legalmente a un sistema concesional basado en la asignación centralizada de derechos por parte del Estado, el que expresamente prohíbe todo uso especial del agua sin permiso o concesión (arts. 110 y 130 LAgM; art. 18 CAgSJ, art. 47 CAgLR; art. 5 LAgC; 25, 142 y 319 CAgS; art. 4 y 10 CAgJ), es usual que en contradicción a ese paradigma se desarrollen aprovechamientos informales, sin ningún tipo de título habilitante previo, en ocasiones de importante significancia económica.

Junto a esas prohibiciones de usos no autorizados, la totalidad de los sistemas jurídicos en análisis especifican que tales irregularidades deben ser sancionadas e impedidas; acorde a ello, disponen mecanismos sancionatorios y medidas de intervención policial tendientes a cesar los usos ilegales.

Así, por ejemplo, se contemplan sanciones pecuniarias ante la utilización de agua de forma ajena a los derechos otorgados, sean por no contar con derecho o sea por realizar un uso mayor al amparado por el mismo (art. 167 LAgM; art. 25 Ley 1920 de Mendoza; arts. 236 y 237 CAgSJ; arts. 16, 184, 263 y 283 CAgLR; arts. 229, 209 y ss LAgC; art. 312 CAgS; art. $275 \mathrm{CAgJ})$.

Junto a las referidas sanciones administrativas, en la República Argentina se ha tipificado como delito la usurpación de aguas, penándose a quienes ilícitamente y con el propósito de causar perjuicio a otro sacare aguas de represas, estanques u otros depósitos, ríos, arroyos, fuentes, canales o acueductos o las sacare en mayor cantidad que aquella a que tenga derecho; al que estorbare el ejercicio de los derechos que un tercero tuviere sobre dichas aguas; y al que ilícitamente y con el propósito de causar perjuicio a otro represare, desviare o detuviere 
las aguas de los ríos, arroyos, canales o fuentes o usurpare un derecho cualquiera referente al curso de ellas (art. 182 Código Penal).

Acorde a ello, incluso algunas legislaciones han contemplado que junto a la instancia sancionatoria administrativa se sustancie el proceso penal (art. 3 Ley 1920 de Mendoza), e incluso han impuesto como deber específico de las autoridades administrativas denunciar las sustracciones ilegales de agua ante las autoridades judiciales competentes, y coadyudar en forma activa y continuada con el Ministerio Público en la represión del delito de usurpación de aguas y de los que resulten tener conexión con este en orden al gobierno y administración del agua pública (arts. 239 y 284 CAgSJ; art. 232 LAgC).

También se ha contemplado la obligación por parte del infractor de compensar el perjuicio sufrido por los usuarios que han visto menguado su caudal, sea mediante compensación de volúmenes si aquel fuere titular de un derecho de agua, o mediante una indemnización administrativa si la compensación en especie no fuere posible (art. 283 CAgSJ).

Sin perjuicio de las responsabilidades sancionatorias, la inmediata cesación de los usos irregulares es otro principio presente en las legislaciones en análisis, lo que se manifiesta en concretas obligaciones de hacer de las autoridades públicas, las que deben disponer la inmediata realización y/o demolición de las obras necesarias u otras medidas para asegurar la imposibilidad de reiteración del aprovechamiento indebido (art. 25 Ley 1920 de Mendoza; art. 284 CAgSJ; art. 65 CAgLR; art. 319 CAgS).

Concordantemente, alguno de los sistemas normativos en análisis, junto a la obligación específica de las autoridades públicas en relación a la cesación de los usos irregulares, estatuyen sanciones hacia los funcionarios que no adopten las medidas pertinentes para impedir usos privativos de aguas sin título que lo autorice (arts. 3 y 25 Ley 1920 de Mendoza; arts. 239 y 249 CAgSJ; art. 65 CAgLR).

En síntesis, en el paradigma de un sistema legal que centraliza el acceso al agua en una decisión estatal formal, la configuración de prácticas propias de un sistema informal, mediante utilizaciones espontáneas que realiza la sociedad al margen de todo uso autorizado, se presenta como una marcada contradicción.

La valoración pública del interés general que procura el régimen formal, entra en crisis ante prácticas individuales, y con ello es una consecuencia necesaria que los usos informales resulten reprimidos. La existencia de tales consecuencias disvaliosas es quizás el punto de contacto con mayor coherencia entre los usos informales y aquellos que cumplen las formalidades legales; coherencia, sin embargo, que no es consistente con otras variantes del ordenamiento que se exponen a continuación.

\subsubsection{Los usos fácticos y su formalización: reconocimiento al valor social del uso del agua}

Una característica predominante en los sistemas normativos analizados es una tendencia a la regularización ex post de las utilizaciones informales existentes mediante su reconocimiento formal dentro del régimen concesional; es decir, los mismos sistemas jurídicos que disponen una asignación formal del uso del agua en forma centralizada y planificada desde el Estado, y la sanción a los usos que han surgido espontánea al margen de esa asignación, también tienden al saneamiento de tales usos de génesis ilegal.

Sin dejar de significar una marcada contradicción con las normas represivas de los usos fácticos, brindar amparo jurídico a dichas utilizaciones es una práctica reiterada, y una importante cantidad de los usos hoy "formalizados" mediante el respectivo título estatal provienen en su génesis de utilizaciones de tipo informal, concretadas inicialmente al margen de la legalidad. 
Así, en Mendoza, en reiteradas ocasiones, Leyes 386, 402, 430, 1920, 2032 y 2274, a la par que se condena y sanciona los usos informales o de hecho existentes, amenazando hacia el futuro a los usuarios irregulares que reiteren esas prácticas y a los funcionarios que las permitan, las normas dan lugar al empadronamiento y regularización de las utilizaciones ilegítimas existentes.

Cano (1967) ha observado sobre estas prácticas que las amenazas de sanción pecuniaria no son suficientes para contrarrestar la plusvalía que general el uso del agua, existiendo una conciencia en quienes realizan los usos irregulares en cuanto a que una vez consolidadas las plantaciones y la consiguiente riqueza social que implican, difícilmente las autoridades ordenarán su destrucción, sino que buscarán el camino para legalizar lo actuado.

La praxis relevada confirma lo observado por el destacado jurista, ya que las experiencias relevadas en las provincias en análisis revelan que la práctica administrativa, más que sancionar, generalmente regulariza mediante permisos precarios las utilizaciones irregulares detectadas.

Posiblemente este desarrollo de políticas de saneamiento legal de usos generados informalmente, de manera "clandestina", como los denomina la legislación local, tenga su fuente en la cultura de oasis fuertemente impregnada en la región, que prioriza la conquista del desierto por sobre otros valores, y donde en los procesos de apropiación los hechos y la distribución de aguas y tierras precedieron y condicionaron el contenido de las normas (Montaña, 2011).

El régimen mendocino, en lo que hace al aspecto en análisis, ha sido replicado en las restantes experiencias normativas vigentes en la región. Así, los arts. 275 y ss. CAgSJ estipulan que por "única vez" los titulares de predios que hayan venido utilizando aguas públicas con habitualidad y connivencia administrativa, pero sin la correspondiente concesión, pueden optar por el cese del uso irregular o la regularización de su uso, sea esto último mediante el traslado de una concesión que titularicen en otro inmueble o mediante la obtención de una nueva concesión. Para esto último, se exige la acreditación del uso preexistente por un plazo de al menos 10 años, y la existencia de cultivos permanentes de al menos 5 años de antigüedad.

Los arts. 285 y ss. CAgLR estipulan el reconocimiento mediante concesión a los usos preexistentes a la norma, tanto si provienen de una concesión anterior a dicho Código, o si se trata de una explotación de hecho que presente una antigüedad no menor a 20 años, pudiendo producirse el empadronamiento por denuncio de los interesados o por relevamiento de usos que practique de oficio la autoridad. En el caso de explotaciones de hecho con una antigüedad menor de 20 años, las mismas serán reconocidas mediante concesión o permiso, por orden de antigüedad y en la medida que exista caudal suficiente, precepto que coincide con la solución genérica que brinda el art. $319 \mathrm{CAgS}$, explayada infra.

Llamativamente, el art. 54 de la norma riojana determina el reconocimiento de los usos sin concesión preexistentes a dicha norma, si su antigüedad es mayor a 20 años, con carácter de concesión permanente, solución que consolida jurídicamente un status legal que privilegia el suministro de los usos ilegales realizados que se formalizan por encima de los usos legalmente desarrollados mediante permisos precarios o concesiones eventuales.

$\mathrm{El}$ art. $229 \mathrm{LAgC}$, al igual que la posteriores Leyes 3074 y 3153, siguen esta misma tendencia, disponiendo que los terrenos cultivados bajo riego que no ostenten un título habilitante, deberán ser denunciados dentro del plazo otorgado a los efectos del trámite concesional, en el que serán considerados a condición de que prueben que los últimos diez años han utilizado dicha agua en explotaciones racionales de valor económico. A su vez, prohíbe en lo sucesivo, sancionando con multa, el uso de agua para regadío sin la correspondiente concesión. 
El art. 319 CAgS acuerda la posibilidad a quienes aprovechen de hecho el agua, sin concesiones ni permisos, para solicitar una concesión conforme a las normas de dicho Código, la que será otorgada siempre que exista caudal suficiente una vez abastecidas las concesiones pedidas con anterioridad. Concluido el plazo para regularizar dichos usos, si los mismos no hubieren sido saneados mediante la correspondiente concesión, la norma dispone la aplicación de las medidas que corresponden ante usos ilegales.

Finalmente, en la Provincia de Jujuy se contempló el reconocimiento, de oficio o a solicitud de parte, de los usos efectivos del agua que de hecho realizados con una antigüedad mayor a diez años a la fecha de la promulgación del Código de Aguas, incluso si eran efectuados por un ocupante sin título de tierra fiscal. En tales casos, la concesión habilita un caudal máximo equivalente al promedio de consumo de los últimos cinco años (art. 285 y ss. $\mathrm{CAgJ})$.

La norma jujeña también reconoce el derecho a los propietarios de inmuebles que se encuentren utilizando aguas subterráneas de solicitar la concesión para el uso que vienen efectuando, la que les será acordada sin otro recaudo que verificar la exactitud de la declaración del uso efectuada. La concesión, sin embargo no podrá tener mayor amplitud que la que podrían obtener los terceros solicitantes bajo el régimen del Código.

\subsection{Mecanismos informales de reasignación contra y praepter legem}

\subsubsection{Mecanismos informales de reasignación de derechos practicados contra legem}

Otra de las facetas en que se manifiesta el acceso al agua mediante mecanismos informales, tiene que ver con prácticas de reasignación del recurso en contraposición a los mecanismos que existen en la institucionalidad formal que fijan las normas.

El relevamiento efectuado en las provincias en estudio permite sostener que el acceso informal al agua, de manera provisoria, es una práctica regular en toda la región. Se generan acuerdos y arreglos informales a nivel distributivo, en ocasiones con participación de autoridades de cauces, permitiendo que el agua que corresponde en una propiedad sea utilizada por otro usuario.

Estos usos, a diferencia de los referidos en los apartados anteriores, no busca en general el desarrollo de cultivos o producciones en propiedades que carecen de derecho, sino más bien reforzar caudales mediante la reasignación transitoria de cupos de aguas entre usuarios. Es decir, no es más que una versión "desinstitucionalizada" de los mecanismos legales de reasignación transitoria de usos de agua que, como el "Registro de Uso de Agua", se encuentra regulado en Mendoza (art. 26 LAgM y Resolución 323/99 HTA)(Pinto, 2004).

Incluso en aquellos casos en que es posible, previa autorización administrativa, la cesión definitiva de derechos de agua (art. 82 y ss. CAgLR; art. 15 LAgC; art. 33 CAgS; art. 22 CAgJ; 107 CAgSJ), también se ha observado la existencia de arreglos realizados sin respetar las formalidades de ley, al margen de la actuación administrativa. En estos casos, incluso, se han generado situaciones de tensión y conflictos entre los adquirentes del derecho de agua cedido informalmente y los posteriores adquirentes del inmueble al que formalmente correspondía la concesión.

Posiblemente, la generación de estas modalidades se produzcan a partir de las dificultades intrínsecas que presentan los sistemas formales de reasignación, muchas veces sometidos a complejos procesos y tiempos burocráticos (Hernandez Mora y De Stefano, 2013), con normas poco claras en el actuar debido, muchas veces desconocidas por los usuarios.

Sin embargo, los niveles de informalismo en la reasignación del recurso que referimos, aunque quizás pueda responder a mayores parámetros de eficiencia en virtud del grado de descentralización en el que se deciden, sin lugar a dudas impactan en la eficacia del sistema normativo que estatuye una distribución bajo parámetros proporcionales de justicia, 
cercenando completamente la transparencia al sistema y facilitando una asignación del agua fundada exclusivamente en el interés particular de las partes intervinientes.

Este tipo de operaciones informales generan, además, un estadio de falta de certeza e inseguridad en los derechos de los usuarios, donde la falta de autorización y la ausente publicidad registral impide hacer oponibles a terceros los derechos informalmente cedidos entre las partes.

Con ello, los mecanismos de reasignación informal del agua que se realizan en conflicto con las formalidades que impone la legalidad se encuentran configurados de manera inestable, resultan acuerdos que carecen de cualquier seguridad jurídica, pudiendo en cualquier momento ser incumplidos por los participantes, desconocidos por terceros interesados, o incluso reprimidos por las autoridades públicas.

\subsubsection{Mecanismos informales de reasignación de derechos practicados praeter legem}

Sin perjuicio de la reasignaciones informales que analizamos como situaciones contra legem, existen experiencias administrativas que, sin habilitar de manera abierta la existencia de arreglos informales o privados, los contempla tácitamente, imponiendo la práctica de transacciones particulares que se realizan sin un marco normativo que las respalde y encauce.

En este sentido, en ciertos casos el régimen normativo no implementa ni regula la posibilidad de que los particulares acuerden en torno a transferencias de agua entre usuarios actuales y futuros, pero exige como condición al inicio trámite de acceso al agua por estos últimos la concurrencia de los primeros a efectos de extinguir, a modo de compensación de caudales, sus derechos.

Es el caso del régimen establecido en la Provincia de Mendoza a partir de la generación de áreas de restricción para efectuar nuevas perforaciones en acuíferos en desbalance (art. 23 LAgSUM, reglamentada por la Resoluciones 673/97 HTA), en el marco de las cuales se ha generado un mercado informal de derechos, no regulado por la autoridad pública (Martin, 2010).

Este mercado informal o negro se ha desarrollado a partir de un régimen reglamentario que originalmente limitaba en tales áreas el acceso a nuevos permisos de perforación mediante la exigencia del cegado previo de un pozo activo o en desuso por un plazo no mayor a un año. Así, los interesados en obtener nuevos permisos de perforación debían transar informalmente con los titulares de las perforaciones a cegar, a efectos de que estos últimos renunciaran a sus derechos y realizaran el cegado de sus pozos, configurándose de esta manera un mercado de derechos de pozos que se caracterizaba, no por la cesión de la concesión propiamente dicha para su uso por un nuevo titular, sino por la conformidad del anterior concesionario a la extinción de su derecho a efectos de que un nuevo peticionante pueda obtener un nuevo derecho.

Con ello, en un sustrato de ausencia regulatoria, quien inicia un trámite para acceder al agua debe, necesariamente, actuar praeter legem, y realizar actos que se encuentran al margen, y en ocasiones incluso en contra, de la ley, generándose antes del trámite concesional una instancia previa de negociación entre el peticionante y un tercero que detenta la titularidad de una perforación, donde acuerdan que éste último brindará su voluntad de renunciar a su derecho a fin de cumplimentar la condición administrativa que permitirá el trámite del nuevo permiso de perforación y la consiguiente concesión de uso de aguas subterráneas. El sistema se instrumenta en un área caracterizada por la ausencia de oferta hídrica, y con ello se impone la aplicación del régimen de prioridades que fija la Ley 4035 de aguas subterráneas; aún así, la regulación vislumbra los nuevos permisos a condición de la renuncia y el cegado de una perforación más antigua, lo que implica beneficiar al solicitante, normalmente comprador de la perforación a cegar, que acredita el acompañamiento de dicha renuncia independientemente de si al mismo corresponde la prioridad legal para obtener el 
permiso, configurando una clara inconsistencia normativa que, si desconoce la referida prioridad, es la base de una asignación ilegal del agua.

Luego de implementado este régimen, estudios técnicos evidenciaron como efectos de este mercado la producción de externalidades negativas. En concreto, se observó que el reemplazo de pozos subutilizados en un sector de la cuenca por nuevas perforaciones destinadas a usos intensivos en otro sector de la misma, generaba un impacto en las reservas y flujos de escurrimiento. Para neutralizar tal efecto, por Resoluciones DGI N ${ }^{\circ}$ 525/08 y 722/11 se impuso que los pozos a cegar debían ubicarse en la misma parcela donde se realizaría la nueva perforación. Sin embargo, esta tendencia precaucional y preventiva, fue posteriormente dejada sin efectos por Resolución DGI $\mathrm{N}^{\circ} 164 / 13$, donde no sólo se habilitó nuevamente que las nuevas perforaciones asienten en una propiedad distinta a la que corresponde a la perforación que se clausura, sino que además se dejó de exigir el uso efectivo de los pozos dados de baja, con lo cual la compensación de caudales que implica el reemplazo devino en abstracto.

De este modo, el esquema normativo reglamentario ha dado lugar a un mecanismo informal de reasignación de aguas, o mercado negro, donde sin ningún tipo de regla estatal en cuanto a la oportunidad, modo y condición en que las operaciones se realizan, los mismos interesados acuerdan la baja de un pozo para reemplazo por otro en forma previa a la nueva solicitud de permiso de perforación.

\section{CONCLUSIONES}

El análisis de la relación entre las regulaciones normativas de asignación y reasignación y los mecanismos informales desarrollados espontáneamente en el oeste argentino revela una serie de contradicciones y tensiones hacia dentro y fuera de los ordenamientos jurídicos.

En general se observa como el Estado a la vez que centraliza el destino del agua y sanciona los usos fuera de tal esquema intervencionista, se legitima poniendo en valor las utilizaciones informales surgidas al margen de la previsión y evaluación estatal. La represión y la regularización o aprobación de las utilizaciones que espontáneamente realizan los miembros de la sociedad son dos principios y actitudes contradictorias que conviven y se suceden mutuamente en la gestión hídrica cotidiana y la regulación.

Aun así, el Estado detenta un rol preponderante en la definición del destino del agua; su papel de representante del interés general lo lleva a controlar usos que se concretan al margen de su dirección, sobre aguas públicas o privadas. Sin embargo, es indudable que en más de una ocasión la autoridad estatal renuncia a ese rol de conductor que le confieren los mecanismos de acceso formal al agua; y tiende a tolerar, o incluso inducir, por diversos motivos, la espontaneidad social en la asignación y reasignación del recurso.

En particular, la presencia de normas que regularizan usos efectuados sin concesión en las distintas normativas analizadas, o que exigen acuerdos o transacciones informales entre particulares como condición previa a que el Estado resuelva sobre nuevos aprovechamientos, como el caso de Mendoza, son prueba de ello, y muestran una tendencia que dinamiza el modelo rígido de asignación estatal centralizada del agua que contemplan las legislaciones, al tiempo que pone en cuestión su naturaleza pública.

Estas tensiones entre las realidades normativas y fácticas que componen el mundo jurídico, a su vez, desnudan una marcada crisis de legitimidad del Derecho estatal de Aguas, donde el contraste de la legalidad con las prácticas sociales y administrativas muestra notables fisuras teóricas y prácticas que desnaturalizan al derecho como principal ordenador de conductas sociales y al Estado como administrador del bien público fundamental que representa el agua en contextos de escasez. 


\section{REFERENCIAS}

ALLEN, A.; DAVILA, J. D.; HOFMANN, P. Gobernabilidad y acceso al agua y saneamiento en la interfaz periurbana: análisis preliminar de cinco estudios de caso. Cuadernos del Cendes, v. 22, n. 59, p. 23-44, 2005. Disponible en: http://www.scielo.org. Accedido el 10 de marzo de 2014.

BOELENS, D.; GETCHES, A.; GUEVARA-GIL, A. (Eds). Out of the Mainstream. Water Rights, Politics and Identity. London: Earthscan; Washington D.C.: Routledge, 2010.

CACERES, D.; RODRIGUEZ-BILELLA, P. Acceso y apropiación del agua en comunidades rurales pobres de Argentina central. Transformaciones y conflictos. Revista Economía, Sociedad y Territorio, v. 14, n. 45, may./ago. 2014.

CANO, G. Reseña crítica de la legislación y administración de aguas de Mendoza. Mendoza: Ed. del Autor, 1967.

CHEVAlliER, J. El Estado posmoderno. Bogotá: Universidad Externado de Colombia, 2011.

FORERO, C. H. Lo justo distributivo: consideraciones desde un caso concreto. Dikaion Revista de Actualidad Jurídica, n. 11, 2002.

FOUCAULT, M. La verdad y las formas jurídicas. Barcelona: Geidisa, 2007.

GARCÍA PERDOMO, D. P.; JIMÉNEZ, F. Reglas formales y no formales de gobernanza del recurso hídrico en la subcuenca del río Ulí, Reserva de la Biosfera Bosawas, Nicaragua. Recursos Naturales y Ambiente, n. 59-60, p. 17-25, mar.-ago. 2010.

GARDAIS ONDARZA, G. El control de legalidad y la eficiencia y eficacia como principios jurídicos fiscalizables. Revista de Derecho de la Pontificia Universidad Católica de Valparaíso, n. 23, p. 323-341, 2002.

GLOBAL WATER PARTNERSHIP. Manejo integrado de recursos hídricos. Estocolmo: GWP, 2000. (Technical Advisory Committee Background Papers, n. 4)

HABERMAS, J. ¿Cómo es posible la legitimidad por vía de legalidad? Doxa, n. 05, p. 37, 1988. Disponible en: http://dialnet.unirioja.es/servlet/articulo?codigo $=3022499$. Accedido el 09 de marzo de 2014.

HERNANDEZ-MORA, N.; DE STEFANO, L. Los mercados informales de aguas en España: una primera aproximación. In: EMBID IRUJO, A. (Dir.). Usos del agua (concesiones, autorizaciones y mercados del agua). Navarra: Aranzadi, 2013.

KEMELMAJER DE CARLUCCI, A. Seguridad y justicia. Jurisprudencia Argentina, p. 812-820, 1993.

MADARIAGA GUTIERREZ, M. Seguridad jurídica y administración pública en el siglo XXI. Santiago: Editorial jurídica de Chile, 1993.

MARTIN, F.; ROJAS, F.; SALDI, L. Domar el agua para gobernar. Concepciones sociopolíticas sobre la naturaleza y la sociedad en contextos de consolidación del Estado provincial mendocino hacia finales del siglo XIX y principios del XX. Anuario del Centro de Estudios Históricos "Prof. Carlos Segreti", año 10, n. 10, p. 159-186, 2010 . 
MARTIN, L. Derecho de aguas. Estudio sobre el uso y dominio de las aguas públicas. Buenos Aires: Abeledo Perrot, 2010.

MONTAÑA, E. Compartir la escasez. Disputas por el agua en Mendoza. In: MIRANDA, O. (Ed.). Estudios sociales del riego en la agricultura argentina. Buenos Aires: INTA, 2011.

NACIONES UNIDAS. Informe sobre desarrollo humano 2006. Más allá de la escasez: Poder, pobreza y la crisis mundial del agua. Madrid: Mundi-Prensa, 2006.

NINO, C. S. Un país al margen de la ley. Buenos Aires: Emecé, 1992.

PAREJO ALFONSO, L. La eficacia como principio jurídico de la actuación de la Administración Pública. Documentación Administrativa, n. 218-219, 1989.

PAUL, W. ¿La irresponsabilidad organizada? Comentarios sobre la función simbólica del derecho ecológico. Revista EI Derecho, n. 136, 1990.

PINTO, M. Mercados de agua y su posible implementación jurídica. La Ley Gran Cuyo, p. 87-96, 2004.

PINTO, M.; TORCHIA, N.; MARTIN, L. El derecho humano al agua. Particularidades de su reconocimiento, evolución y ejercicio. Buenos Aires: Abelardo Perrot, 2008.

REIS, N. Coyotes, concessions and construction companies: Illegal water markets and legally constructed water scarcity in central Mexico. Water Alternatives, v. 7, n. 3, p. 542560, 2014.

SPOTA, A. Lo político, lo jurídico, el derecho y el poder constituyente. Buenos Aires: Plus Ultra, 1975.

SUPIOT, A. Homo juridicus. Ensayo sobre la función antropológica del derecho. Buenos Aires: Siglo Veintiuno, 2012. 